\title{
Can proximal femoral nailing of unstable trochanteric fractures help to regain pre-injury functional status in Indian rural patients? A prospective study of functional outcome of unstable intertrochanteric fractures with proximal femoral nailing
}

\author{
Shankar Linga S. ${ }^{1}$, Janardhana Aithala P. ${ }^{2}$, Amarnath Savur ${ }^{2}$ \\ ${ }^{1}$ Department of Orthopedics, KMC Mangalore, Manipal University, Karnataka, India \\ ${ }^{2}$ Yenepoya Medical College, Mangalore, Karnataka, India
}

Received: 20 April 2017

Accepted: 08 May 2017

*Correspondence:

Dr. Shankar Linga S.,

E-mail: shankyasajjan@gmail.com

Copyright: $\odot$ the author (s), publisher and licensee Medip Academy. This is an open-access article distributed under the terms of the Creative Commons Attribution Non-Commercial License, which permits unrestricted non-commercial use, distribution, and reproduction in any medium, provided the original work is properly cited.

\section{ABSTRACT}

Background: In view of the high incidence of implant failure and varus collapse seen in unstable inter trochanteric femur fractures treated with dynamic hip screw (DHS), proximal femoral nailing (PFN) has gained popularity. ${ }^{1,2}$ However there is limited literature regarding functional outcome following PFN especially in Indian patients. In this study, our aim was to assess functional outcome following PFN of unstable inter trochanteric femur fractures which includes the ability to sit cross legged and squat.

Methods: This prospective observational study was done at the associated hospitals of KMC Mangalore, spanning a time period of around 2 years, from October 2014 to July 2016. All patients who presented with isolated closed unstable inter-trochanteric fractures were included in the study. Patients were treated with proximal femoral nailing and followed up for a minimum period of 6 months. Outcome measures included Harris hip score, walking status and ability to sit cross legged and squat.

Results: 40 consecutive patients (Mean age 61 years, range 25-95) were included in the study, all fractures united within 6 months. As per Harris hip score, 25 patients $(62.5 \%)$ had excellent or good results, 8 patients (20\%) had fair and 7 patients (17.5\%) had poor results. 74\% (20 out of 27) regained their gainful working status. $80 \%$ (24 out of 30) were able to squat easily or with some difficulty and $74 \%$ (20 out of 27 ) patients were able to sit cross legged with or without difficulty. $82 \%$ (23 out of 28 ) regained their unassisted walking status.

Conclusions: For unstable inter trochanteric femur fracture PFN gives good results in terms of union, walking ability and majority of the patients regained their pre injury activity status including squatting and cross leg sitting.

Keywords: Trochanteric fractures, Proximal femoral nailing, Functional outcome

\section{INTRODUCTION}

Although surgical stabilization of unstable inter trochanteric femur fractures have become popular in view of complications related to confinement to bed following conservative management, the ideal implant for surgical stabilization of the same, however, is still a debate. ${ }^{1}$ Dynamic hip screw (DHS) was considered as the gold standard for most of the inter trochanteric femur fractures. ${ }^{2}$ However, in unstable trochanteric fractures, it is associated with high complications (15-21\%) like varus collapse, screw back out and cut out of implant from femoral head. ${ }^{2,3}$ In view of this, intra medullary devices like proximal femoral nail are becoming popular. ${ }^{3}$ Theoretically, biomechanical advantages of intramedullary nail over screw and plate fixation are attributed 
to the reduced distance between hip joint and the implant, restoration of medial cortical continuity and preservation of lateral wall in intra-medullary nailing which gives good results in unstable inter trochanteric fractures. ${ }^{3}$ In practice too, many authors have studied and found out that PFN compares favorably with DHS in terms of surgical time, intra operative blood loss and lag screw cut out in unstable inter trochanteric fracture. ${ }^{3-6}$ However, most of these studies failed to convince the superiority of $\mathrm{PFN}$ in terms of functional outcome. There are only a few studies which have studied the functional outcome. ${ }^{4,7} \mathrm{~J}$. Pajarinen et al, found that about $23 \%$ of the total patients with unstable inter trochanteric fractures treated by PFN were not able to reach their pre injury walking ability, although the results were better when compared to the DHS group (46\% patients). ${ }^{4}$ In the limited literature available, only a handful of studies highlight the functional recovery in comparison to pre injury status following surgical fixation of these fractures.

In the Indian context, when we want to analyze functional outcome; in addition to walking status, our people also would like to sit crossed leg and squat. ${ }^{8}$ In elderly patients, inability to squat may be natural outcome of ageing phenomena, but still a few patients would be interested to know whether they can perform these activities. To the best of our knowledge, this has not been studied in detail. Thus our study aim was to assess the functional outcome following PFN of unstable inter trochanteric femur fractures which includes the ability to sit cross leggged and to squat.

\section{METHODS}

This prospective observational study was done at the associated hospitals of KMC Mangalore from October 2014 to July 2016. Ethical committee clearance was taken from Kasturba Medical College, Mangalore (IEC KMC MLR 10-14/206). Total Sample size was 40 and was calculated using the formula $n=z_{\alpha}^{2} p q / E^{2}$ where $\mathrm{z}=1.96(95 \%)$ with $95 \%$ confidence and $80 \%$ power. All patients who presented with isolated closed unstable inter-trochanteric fractures (modified Evans 3, 4, 5 and reverse oblique) and who were willing for surgery were included in the study ${ }^{9}$. Both the authors classified the fractures separately to study the intra observer variation for fracture classification and senior author's classification was accepted at the end. The first 40 consecutive patients (as per sample size), with a minimum 6 months follow up, were included in the study. Patients presenting with open fractures, pathological and old neglected fractures were excluded. At the time of presentation, data regarding pre injury walking status, working status, ability to squat and sit cross legged were noted.

All patients were treated with proximal femoral nailing (stainless steel, Indian make) and post operatively patients were evaluated with radiographs to check the position of head screw, quality of reduction and neck shaft angle. Neck shaft angle was measured using surgimap by drawing a line from centre of femoral head along the axis of neck and one line along the long axis of shaft of femur. Screw position was judged by dividing the head of femur into 9 quadrants using both AP and Lateral view $\mathrm{x}$ rays. ${ }^{10}$ Patients were followed for minimum 6 months. At the final follow up functional outcome was assessed by Harris hip score, walking status, ability to squat and sit cross legged. Fisher exact test was done to study the correlation between the factors that predict functional outcome (such as age, co morbidities, the type of fracture, neck shaft angle and tip apex distance, pre injury walking status, pre injury status with regard to sitting cross legged and squatting) with the functional outcome. Harris hip score was graded as excellent (90$100)$, good (80-89), fair (70-79) and poor $(<70) .^{11}$

\section{RESULTS}

As our study objective was to have 40 patients with complete follow up, we had to enroll a total of 63 patients, out of which 3 expired, 20 were unavailable, thus 40 patients were available for final follow up.

Pre-operative characteristics of enrolled patients are given in Table 1.

Table 1: Base line data.

\begin{tabular}{|c|c|}
\hline Pre fracture baseline data & $\mathrm{N}=\mathbf{4 0}$ \\
\hline Age & Mean: 61 years $(25-95)$ \\
\hline \multirow{2}{*}{ Sex } & Male: 21 \\
\hline & Female: 19 \\
\hline \multirow{2}{*}{$\begin{array}{l}\text { Co-morbidities (diabetes } \\
\text { mellitus, ischemic heart } \\
\text { disease, renal failure etc.) }\end{array}$} & Yes: $16(40 \%)$ \\
\hline & No: $24(60 \%)$ \\
\hline \multirow{4}{*}{$\begin{array}{l}\text { Type of fracture (as per } \\
\text { Evan's classification) }\end{array}$} & Type 3: $14(35 \%)$ \\
\hline & Type 4: $11(27.5 \%)$ \\
\hline & Type 5: $08(20 \%)$ \\
\hline & $\begin{array}{l}\text { Reverse oblique: } 07 \\
(17.5 \%)\end{array}$ \\
\hline \multirow{4}{*}{ Pre injury walking status } & Unaided: 28 (70\%) \\
\hline & $\begin{array}{l}\text { Aided with } 1 \text { stick: } 07 \\
(17.5 \%)\end{array}$ \\
\hline & Walker: 04 (10\%) \\
\hline & Bed ridden: $01(2.5 \%)$ \\
\hline \multirow{4}{*}{ Pre injury working status } & $\begin{array}{l}\text { Gainful work: } 27 \\
(67.5 \%)\end{array}$ \\
\hline & $\begin{array}{l}\text { Restricted to house hold } \\
\text { activities: } 07(17.5 \%)\end{array}$ \\
\hline & $\begin{array}{l}\text { Restricted to personal } \\
\text { activities: } 05(12.5 \%)\end{array}$ \\
\hline & $\begin{array}{l}\text { Dependent on others: } 01 \\
(2.5 \%)\end{array}$ \\
\hline \multirow{2}{*}{ Pre injury squatting } & Yes: $30(75 \%)$ \\
\hline & No: $10(25 \%)$ \\
\hline $\begin{array}{l}\text { Pre injury sitting crossed } \\
\text { leg }\end{array}$ & $\begin{array}{l}\text { Yes: } 27(67.5 \%) \\
\text { No: } 13(32.5 \%)\end{array}$ \\
\hline
\end{tabular}


Post-operative radiographs were analysed after surgery and key operative and radiological features are given below.

Table 2: Operative and radiological data following fixation.

\begin{tabular}{|c|c|}
\hline \multirow{2}{*}{ Type of implant used } & Short PFN: 32 (80\%) \\
\hline & Long PFN: 08 (20\%) \\
\hline \multirow{7}{*}{ Position of hip screw } & Center, center: $36(90 \%)$ \\
\hline & Center anterior: $01(2.5 \%)$ \\
\hline & Center posterior: $02(5 \%)$ \\
\hline & Superior: $01(2.5 \%)$ \\
\hline & Inferior center: 0 \\
\hline & Inferior anterior: 0 \\
\hline & Inferior posterior: 0 \\
\hline \multirow{2}{*}{ Neck shaft angle } & Below 120: $09(22.5 \%)$ \\
\hline & Above 120: $31(77.5 \%)$ \\
\hline \multirow{3}{*}{ Tip apex distance } & Less than $10 \mathrm{~mm}: 0$ \\
\hline & $10-25 \mathrm{~mm}: 36$ \\
\hline & More than 25:04 \\
\hline
\end{tabular}

One patient had developed proximal femur fracture intraoperatively, but fracture showed union by 6 months. All the fractures were united by the end of 6 months follow up. There were 4 complications, screw back out in 3 patients, screw back out with varus collapse in one patient. Out of these 4 patients, 2 were bed ridden while other two were able to walk unaided.

Table 3: Shows the results, using various functional parameters.

\begin{tabular}{|c|c|}
\hline Final follow up & $\mathrm{N}=40$ \\
\hline \multirow{4}{*}{ Harris hip score } & Excellent: $08(20 \%)$ \\
\hline & Good: $17(42.5 \%)$ \\
\hline & Fair: $08(20 \%)$ \\
\hline & Poor: $07(17.5 \%)$ \\
\hline \multirow{4}{*}{ Working status } & Gainful work: $20(50 \%)$ \\
\hline & $\begin{array}{l}\text { Restricted to house hold } \\
\text { activities: } 09(22.5 \%)\end{array}$ \\
\hline & $\begin{array}{l}\text { Restricted to personal activities: } \\
08(20 \%)\end{array}$ \\
\hline & Dependent on others: 03 (7.5\%) \\
\hline \multirow{4}{*}{ Walking status } & Unaided: $23(57.5 \%)$ \\
\hline & Aided with 1 stick: 03 (7.5\%) \\
\hline & Walker: $12(30 \%)$ \\
\hline & Bed ridden: $02(05 \%)$ \\
\hline \multirow{2}{*}{ Squatting } & Yes: $24(60 \%)$ \\
\hline & No: $16(40 \%)$ \\
\hline \multirow{2}{*}{ Sitting crossed leg } & Yes: $20(50 \%)$ \\
\hline & No: $20(50 \%)$ \\
\hline
\end{tabular}

Among the variables, age $(\mathrm{p}=0.014)$ and co morbidities $(\mathrm{p}=0.010)$ bear significant effect on the functional outcome.
Following table (Table No. 4) shows the results of Fischer Exact test to study the correlation between Harris hip score and variables which can affect the functional outcome.

Table 4: Shows correlation between Harris hip score and variables which can affect the functional outcome.

\begin{tabular}{|ll|}
\hline $\begin{array}{l}\text { Correlation of variables with Harris hip } \\
\text { score }\end{array}$ & P value \\
\hline Age - Harris hip score & 0.014 \\
\hline $\begin{array}{l}\text { Type of fracture ( Evan's) - Harris hip } \\
\text { score }\end{array}$ & 0.226 \\
\hline Co morbidities -Harris hip score & 0.010 \\
\hline Short/Long PFN - Harris hip score & 0.062 \\
\hline $\begin{array}{l}\text { Placement of hip screw - Harris hip } \\
\text { score }\end{array}$ & 0.131 \\
\hline Neck shaft angle - Harris hip score & 0.545 \\
\hline
\end{tabular}

Correlation between pre-injury and final walking, squat and sitting cross legged status are shown in graph 1,2 and 3 .

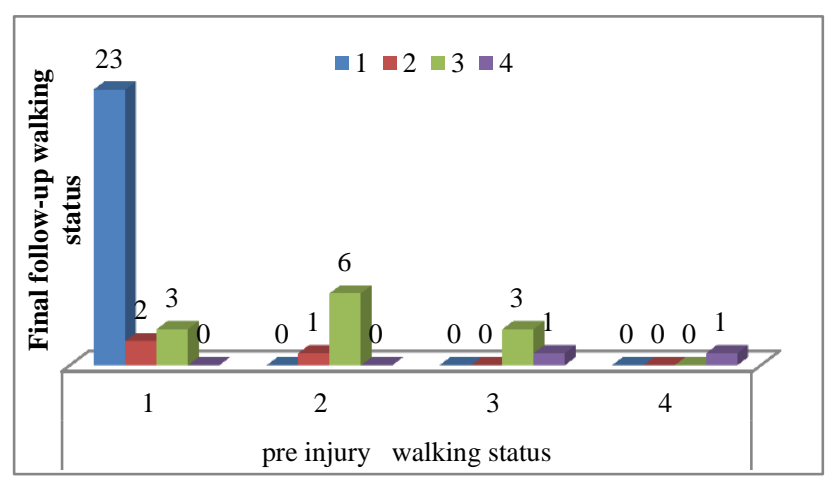

Figure 1: Walking status.

1: unaided, 2: with 1 stick, 3: walker, 4: bed ridden.

Twenty eight patients were walking unassisted during their pre injury level, out of which 23 regained their walking status, 02 were walking with stick and 3 dependent on walker.



Figure 2: Squatting status. 
Thirty patients were able to squat during pre-injury level, out of which twenty four regained their initial status and rest all had restriction in that activity.

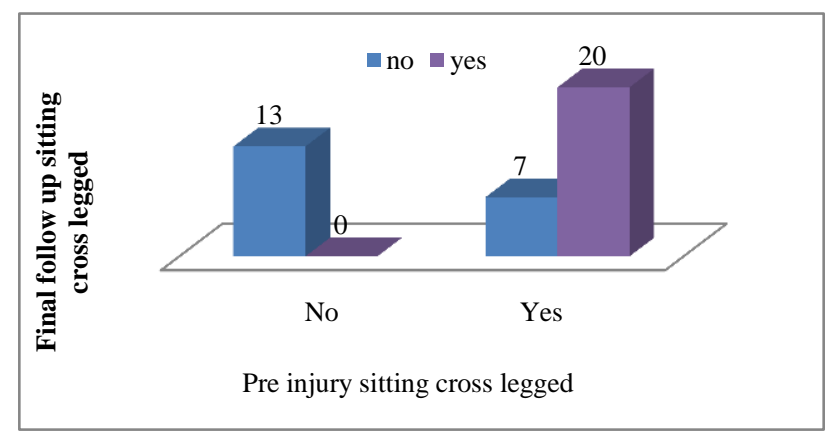

Figure 3: Sitting cross legged status.

Out of twenty seven patients who were able to sit cross legged during pre-injury level, twenty regained their status and rest were unable to do.

\section{DISCUSSION}

Inter trochanteric fractures are the most common fractures that occur in elderly people with osteoporotic bones. ${ }^{12}$ It also occurs in young individuals usually due to high energy trauma. Non-operative management of these fractures lead to serious complications like deep vein thrombosis, aspiration pneumonia and decubitus ulcer. It may also lead to fracture mal union and associated shortening of limb. ${ }^{13-17}$

The ideal implant for the surgical management of unstable intertrochanteric femur fractures is still a matter of debate. Until recently dynamic hip screw was the implants of choice for management of inter trochanteric femur fractures, but this implant doesn't give satisfactory results in case of unstable fractures., ${ }^{2,14-22}$ The reason behind the failure is thought to be due to the longer lever arm, which is placed away from the mechanical axis of the body making it a load bearing device instead of a load shearing one. In view of the failure of the DHS system in the form of varus collapse, implant failure and excessive sliding, intra medullary devices like PFN gained popularity due to its load shearing action and the already mentioned biomechanical advantages over the DHS. ${ }^{24,25}$ Although PFN is biomechanically a better implant and can be done with minimal invasive approach, functional outcome following PFN specifically in unstable fracture is not well documented. Besides in Indian context, we wanted to know whether these patients will be able to squat and sit cross legged as these are important in Indian context. Many of patients in our country are from rural background and these patients will be more keen to resume their day to day activities which includes sitting in floor and squatting.

We included consecutive 40 unstable trochanteric fractures and hence we feel this is our strength of study without selection bias. In our series we included type 3,
4, 5 and reverse oblique fractures according to modified Evans and we did not find any difference in outcome and we believe that irrespective of whether its medial or lateral wall comminution or reverse oblique, $\mathrm{PFN}$ gives similar results. We feel most of the cases of trochanteric fractures will unite within 6 months as seen in our study and hence assessment at 6 months was adequate although 2 year follow up was desirable and is one of the limitation of this study. However, functional disability can be a normal ageing process and hence there can be some functional disability due to age after 2 years and hence we wanted to study functional recovery status at 6 months. We did not find any literature evidences on functional outcome analyzed based on type of fractures. There are few reports that study the functional outcome of these fractures by the Harris hip score. Pajarinen et al series shows $76.2 \%$ good to excellent Harris hip score with a mean of $66.8 \%$ and Schipper et al series found $77.6 \%$ good to excellent results and our study found $62.5 \%$ good to excellent Harris hip score. ${ }^{4,25}$ We achieved almost similar results to the above quoted one. At the best of my knowledge, functional outcome including squatting and sitting crossed leg in Indian populations have not been studied in detail. In our study $80 \%$ achieved their pre injury squatting and $74 \%$ achieved sitting crossed leg status. We feel, it is a good result considering the nature of fracture as well as age.

We now analysed factors which contributed to good results. Good functional outcome depends on variables like neck shaft angle, hip screw position and tip apex distance. In our study we achieved optimal neck shaft angle and hip screw position, hence all our fractures united with minimal implant related complication. Except one patient, all patients in our study had a neck shaft angle of more than 120 degrees, which shows proper reduction and restoration of normal anatomical neck shaft alignment and these patients showed good to excellent functional outcome. Pajarinen et al in his series of 41 patients treated trochanteric fractures with PFN, found significant statistical difference in functional out come of patients with reduced neck shaft angle. ${ }^{4}$

Our placement of hip screw in centre/centre position in most of the cases, also has contributed to good result in our series. Baumgaertner et al documented that the optimal placement of the lag screw was in the centre/centre position. ${ }^{5}$ The correct placement of the lag screw at the centre of the femoral head and neck is important in both the antero-posterior and axial views in order to prevent screw back outs, because centre position of the femoral head is strongest portion and it holds the screw strongly and thereby prevents screw back out.

With regard to implant related complications, in our study we found 4 reverse Z-effect, functional outcome was poor in 2 of these patients who are bedridden, other 2 regained their functional status in the final follow up. All 4 of these patients had tip apex distance more than $25 \mathrm{~mm}$ which might have been the reason for the same. Papasimos et al series found $3 \mathrm{Z}$-effect and 1 reverse Z- 
effect. $^{7}$ Geller et al in their series found that $44 \%$ of cut out rates in patients with tip apex distance more than $25 .^{24}$ In our study we encountered one $(2.5 \%)$ intra operative proximal femur fracture due to inadequate reaming of proximal fragment. But this patient achieved fracture union within 6 months and functionally able to squat and sitting cross legged. Yaozeng et al reported $6(5.6 \%)$ intra operative femoral shaft fractures in their series of 107 inter trochanteric fractures. ${ }^{23}$ Adequate reaming of the femoral canal, especially when using longer nails, can decrease the incidence of this complication.

Apart from a few complications, we achieved proper neck shaft angle and hip screw position, which are the important factors in determining good reduction.

Importance of proper neck shaft angle was highlighted earlier also by our senior author's previous study. ${ }^{26}$ Thus most of the variables which contribute to good functional outcome like quality of reduction (as assessed by neck shaft angle), position of hip screw (as assessed by position of screw tip in nine quadrants and tip apex distance) are under our control and if proper care has been taken during nail placement, we feel good results can be obtained with PFN in unstable trochanteric fracture. Our senior author has already dealt with the technical details on how to achieve optimal fixation in his previous article. $^{26}$

Among the variables which are not under our control, age ( $p=0.014)$ and co morbidities $(p=0.010)$ have significant bearing on the functional outcome. In our studies old aged and co morbid patients showed poor functional score due to delay in mobilization and their general health conditions. Whereas young and middle aged patients showed better functional out come and most of them regained their functional status. Pre injury walking status, squatting and sitting cross legged also affected the final functional outcome. People who were able to squat and sit cross legged at pre injury level; showed $80 \%$ squatting and $74 \%$ sitting cross legged at final follow up.

\section{CONCLUSION}

For unstable inter trochanteric femur fracture PFN gives good results in terms of union, walking ability and majority of the patients regained their pre injury activity status including squatting and sitting cross legged.

Funding: No funding sources Conflict of interest: None declared

Ethical approval: The study was approved by the institutional ethics committee

\section{REFERENCES}

1. Kaufer H, Matthews LS, Sonstegard D. Stable fixation of intertrochnatric fractures. J Bone Joint Surg Am. 1974;56(5):899-907.

2. Hsueh KK, Fang CK, Chen CM, Su YP, Wu HF, Chiu FY. Risk factors in cutout of sliding hip screw in intertrochanteric fractures: an evaluation of 937 patients. Int Orthop. 2010;34(8):1273-6.

3. Fogagnolo F, Kfuri M Jr, Paccola CA. Intramedulary fixation of pertrochanteric hip fractures with short AO-ASIF proximal femoral nail. Arch Orthop Trauma Surg. 2004;124(1):31-7.

4. Pajarinen J, Lindahl J, Michelsson O, Savolainen V, Hirvensalo E. Pertrochanteric femoral fractures treated with a dynamic hip screw or a proximal femoral nail: a randomized study comparing postoperatice rehabilitation. J Bone Joint Surg. 2005;87(1):76-81.

5. Baumgaertner MR, Curtin SL, Lindskog DM. Intramedullary versus extramedullary fixation for the treatment of intertrochanteric hip fractures. Clin Orthop Relat Res. 1998;384:87-94.

6. Hardy DC, Descamps PY, Krallis P, Fabeck L, Smets P, Bertens CL, et al. Use of an intramedullary hip-screw compared with a compression hi[-screw with plate for intertrochanteric femoral fractures. A prospective, randomized study of one hundred patients. J Bone Joint Surg Am. 1998;80(5):618-30.

7. Papasimos S, Koutsojannis C M, Panagopoulos A, Megas P, Lambris E. A randomized comparison of AMBI, TGN and PFN for treatment of unstable trochanteric fractures. Arch Orthop Trauma Surg. 2005;125(7):462-8.

8. Pervez H, Parker MJ, Pryor GA, Lutchman L, Chirodian N. Classification of trochanteric fracture of the proximal femur: a study of the reliability of current systems. Injury. 2002;33(8):713-5.

9. Evans EM. The treatment of trochanteric fractures of the the femur. $\mathrm{J}$ Bone Joint Surg Br. 1949;31(2):190-203.

10. Cleveland M, Bosworth D M, Thompson F R. Intertrochanteric fractures of the femur: a survey of treatment in tractin and by internal fixation. J Bone Joint Surg Am. 1947;29(4):1049-82.

11. Harris WH. Traumatic arthritis of the hip after dislocation and acetabular fractures: treatment by mold arthroplasty. An end-result study using a new method of result evaluation. J Bone Joint Surg Am. 1969;51(4):737-55.

12. Rockwood, Green DP, Bucholz RW, Fleckrnan JD, Court-Brown CM. Rockwood and Green's fracture in adults. 2010;2(6):1827-44.

13. Ansari Moein CM, Verhofstad M H, Bleys R L, van der Werken. Soft tissue injury related to the choice of entry point in antegrade femoral nailing: pyriform fossa or greater trochanter tip. J Clin Orthop Injury. 2005;36(11):1337-42.

14. Babhulkar SS. Management of trochanteric Fractures. Indian J Orthop. 2006;40(4):210-18.

15. Banan H, Al-Sabti A, Jimulia T, Hart AJ. The treatment of unstable, extracapsular hip fractures with the AO/ASIF proximal femoral nail (PFN)our first 60 cases. Injury. 2002;33(5):401-5.

16. Brumback RJ, Uwagie-Ero S, Lakatos RP, Poka A, Bathon GH, Burgess AR. Intramedullary nailing of femoral shaft fractures. Part II: Fracture-healing 
with static interlocking fixation. J Bone Joint Surg Am. 1988;70(10):1453-62.

17. Gadegone WM, Salphale YS. Short proximal femoral nail fixation for trochanteric fractures. J Orthop Surg HK. 2010;18(1):39-44.

18. Bannister GC, Gibson AG, Ackroyd CE, Newman JH. The fixation and prognosis of trochanteric fractures: a randomized prospective controlled trial. Clin Orthop Relat Res. 1990;254:242-6.

19. Esser MP, Kassab JY, Jones DH. Trochanteric fractures of the femur: a randomised prospective trial comparing the Jewett nailplate with the dynamic hip screw. J Bone Joint Surg Br. 1986;68(4):557-60.

20. Heyse-Moore G H, MacEachern A G, Evans D C. Treatment of intertrochanteric fractures of the femur: a comparison of the Richards screw-plate with the Jewett nail-plate. J Bone Joint Surg Br. 1983;65(3):262-7.

21. Jacobs RR, Armstrong HJ, Whitaker JH, Pazell J. Treatment of intertrochanteric hip fractures with a compression hip screw and nail plate. J Trauma. 1976;16:599-603.

22. Parker MJ, Handoll HH. Gamma and other cephalocondylic intramedullary nails versus extramedullary implants for extracapsular hip fractures in adults. Cochrane Database Syst Rev. 2010;(9):CD000093.
23. Yaozeng X, Dechun G, Huilin Y, Guangming Z, Xianbin W. Comparative study of trochanteric fracture treated with the proximal femoral nail antirotation and the third generation of gamma nail. Injury. 2010;41(12):1234-8.

24. Geller JA, Saifi C, Morrison TA, Macaulay W. Tipapex distance of intramedullary devices as a predictor of cut-out failure in the treatment of peritrochanteric elderly hip fractures. Int Orthop. 2010;34(5):719-22.

25. Schippera IB, Marti RK, van der Werken C. Unstable trochanteric femoral fractures: Extramedullary or intramedullary fixation. Review of literature. Injury. 2004;35(2):142-51.

26. Aithala JP, Rao S. Proximal Femoral Nailing: Technical Difficulties and Results in Trochanteric Fractures. Open J Orthop. 2013;3(5):234-42.

Cite this article as: Linga SS, Aithala JP, Savur A. Can proximal femoral nailing of unstable trochanteric fractures help to regain pre-injury functional status in Indian rural patients? A prospective study of functional outcome of unstable intertrochanteric fractures with proximal femoral nailing. Int J Res Orthop 2017;3:728-33. 